\title{
Aplikasi Sistem Perpustakaan SMP ISLAM YASMIN Berbasis JAVA
}

\author{
Mahir $^{1}$, Muhammad Haikal ${ }^{2}$, dan Dian Nur Sholihaningtias ${ }^{3}$ \\ 1,2,3 Universitas Indraprasta PGRI \\ J1. Raya Tengah No.80, RT.6/RW.1, Kel. Gedong, Kec. Pasar Rebo \\ Kota Jakarta Timur, Daerah Istimewa Jakarta 13760 \\ 1․mahirseff@gmail.com, ${ }^{2}$ high_c4l1@yahoo.com, ${ }^{3}$ Dian.tyash@gmail.com
}

\begin{abstract}
Abstrak - Perpustakaan merupakan unit penunjang pendidikan yang harus memberikan informasi dan pengetahuan kepada peserta didik sebab didalam perpustakaan itulah mereka bisa menemukan banyak pengetahuan informasi, sehingga peserta didik memiliki wawasan luas. Sistem perpustakaan di SMP Islam Yasmin ini masih menggunakan cara konvensional atau manual dalam kegiatan sehari - hari sehingga sering terjadi kesalahan dalam memasukan data, Keterlambatan dalam proses pencarian data yang diperlukan serta penumpukan arsip yang tidak teratur. Dengan berdasarkan permasalahan yang ada tersebut maka dibuatlah suatu perangkat lunak yang bisa memberi solusi untuk membantu petugas perpustakaan dalam mengelola data - data perpustakaan di SMP Islam Yasmin serta dapat mempercepat transaksi peminjaman dan pengembalian buku oleh siswa.
\end{abstract}

Kata kunci: Sistem, Sistem Informasi, Perpustakaan, Java

Abstrak - Library is a supporting educational unit that must provide information and knowledge to learners because in their environment they can share information, so that learners have broad insight. The library system in SMP Islam Yasmin is still using conventional or manual way in daily activities so that there are often mistakes in entering data, delay in the process of finding the necessary data and the accumulation of irregular archives. With the existing problem-based then created a software that can provide solutions to help librarians in the parent data - library data in SMP Islam Yasmin and can accelerate student borrowing and repaying transactions.

Keyword: System, Information System, Library, Java

\section{Pendahuluan}

[1] Perpustakaan sekolah merupakan salah satu fasilitas yang disediakan oleh sekolah sebagai pendukung dan penunjang proses kegiatan belajar mengajar bagi para siswa. Keberadaan sebuah perpustakaan sangat membantu untuk menambah atau meningkatan pengetahuan dan wawasan bagi para murid di sekolah. Dengan meningkatnya fungsi perpustakaan secara maksimal maka diharapkan juga akan memberikan pendidikan yang maksimal bagi para murid [2]. Salah satu langkah yang bisa diterapkan untuk meningkatkan fungsi perpustakaan sekolah adalah dengan menggunakan sistem pengolahan data yang tepat dan cepat. Sistem aplikasi perpustakaan yang dibutuhkan oleh sekolah nantinya dipergunakan untuk tujuan pencatatan, pengolahan, penyimpanan, melihat kembali dan juga untuk menyalurkan informasi itu sendiri.

Sedangkan sistem perpustakaan [3] yang digunakan oleh SMP ISLAM YASMIN adalah sistem perpustakaan yang masih manual, yaitu cara peminjaman dan pengembalian buku pada perpustakaan tersebut adalah dengan masih menggunakan tulisan tangan. Seringkali buku yang akan dipinjam oleh siswa tidak didapat diperoleh walaupun buku tersebut ada di perpustakaan. Hal itu terjadi karena sistem dalam pencarian buku masih manual. Dengan adanya sistem yang akan di bangun,maka saya berharap hal tersebut tidak akan terjadi lagi, karena sisitem komputerisasi akan lebih sangat menunjang siswa/i dalam mencari buku yang mereka inginkan.

\section{Tinjauan Pustaka}

2.1. Perancangan

[4] Perencananaan suatu sistem yang menyangkut berbagai rancangan sehingga akan menghasilkan sistem yang sesuai dengan hasil dari tahap analisa system yang kita buat.

2.2. Sistem

sistem yaitu komponen yang saling berhubungan dan saling berinteraksi satu sama lain untuk dimana sitem yang biasanya terbagi dalam sub sistem yang lebih kecil untuk mendukung sistem yang lebih besar [5].

2.3. Diagram Alir Data

[6] Data Flow Diagram yang grafik menggambarkan aliran informasi dan transformasi yang diaplikasikan sebagai data yang mengatur dari masukan (Input) dan keluar (Ouput). 


\subsection{Mysql}

[7] MySQL server basis data yang mampu menerima dan mengirimkan data dengan cepat menggunakan perintah-perintah SQL.

\subsection{Java}

Java dapat dijalankan diberbagai computer [8]. Java berdiri disebuah mesin yang diberinama Java Virtual Machine (JVM).

\subsection{Netbeans}

Netbeans open source yang sering kali diasosiasikan dengan Java [9]. Akan tetapi IDE untuk membuat proyek-proyek Java saja, melainkan juga proyek seperti web service.

\section{Metode Penelitian}

Metode penelitian yang peneliti gunakan untuk mendapatkan informasi serta data-data yang diperlukan yaitu menggunakan metode deskriptif dengan tujuan untuk mendapatkan data secara detail, mendalam, dan juga aktual.

Maka peneliti melakukan metode pengumpulan data antara lain:

1. Metode observasi (Pengamatan langsung)

Peneliti dengancara pengamatan langsung kelapangan serta mengamati sistem yang sedang berjalan.

2. Metode interview (Wawancara)

Peneliti melakukan tanya jawab kepada kepala perpustakaan, yang berkaitan dengan masalah agar dapat di pecahkan sehingga memperoleh data-data yang benar-benar akurat.

3. Metode Studi Kepustakaan (Literature)

Metode pengummpulan data yaitu mempelajari literature baik berupa dokumen tertulis dan berupa gambar serta mengambil teori-teori yang berhubungan dengan judul penelitian ini.

\section{Hasil dan Pembahasan}

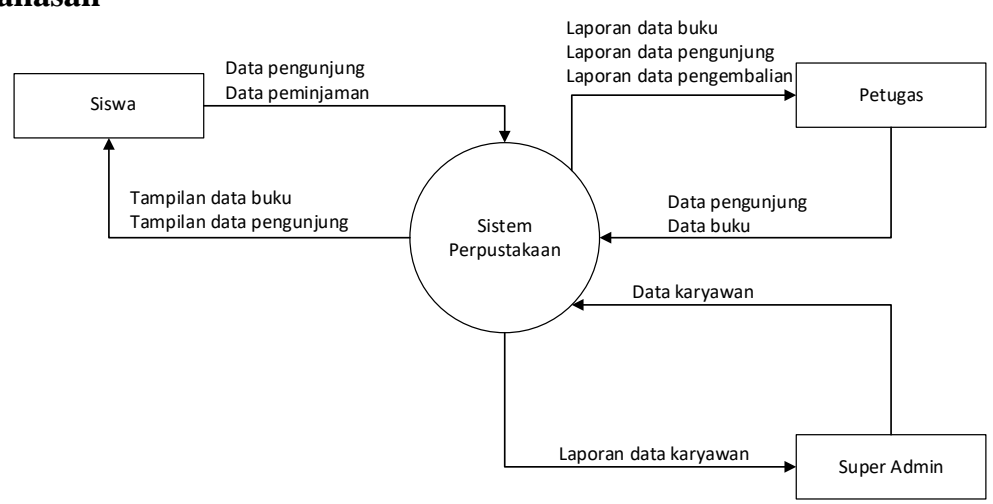

Gambar 1. Diagram Konteks Sistem yang Diusulkan

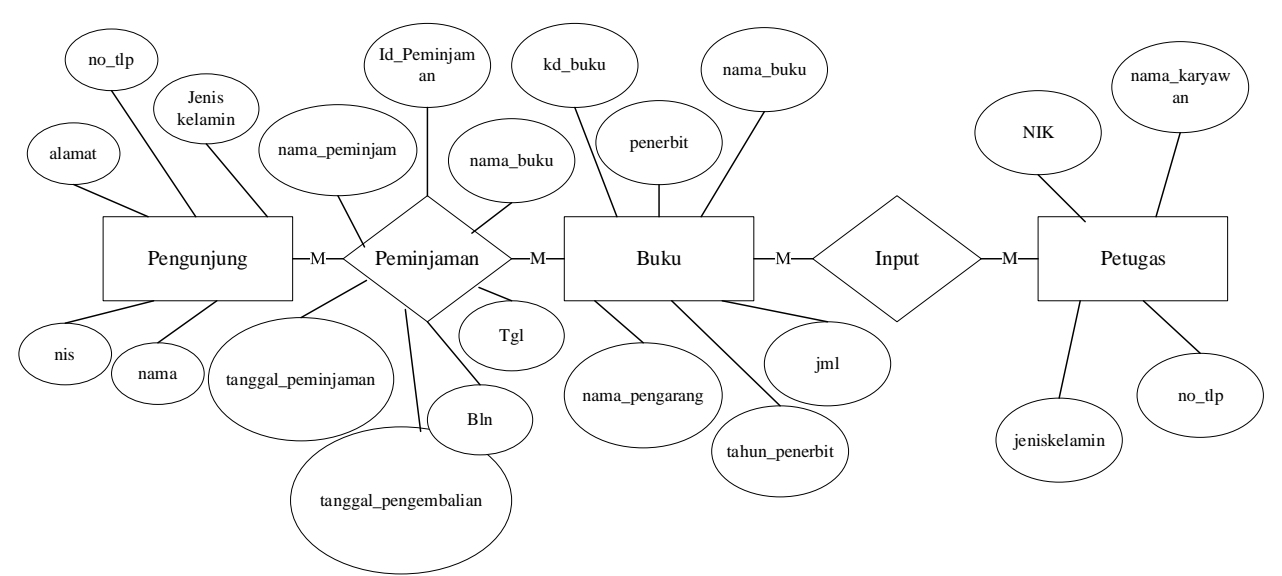

Gambar 2. Entity Relationship Diagram (ERD) 


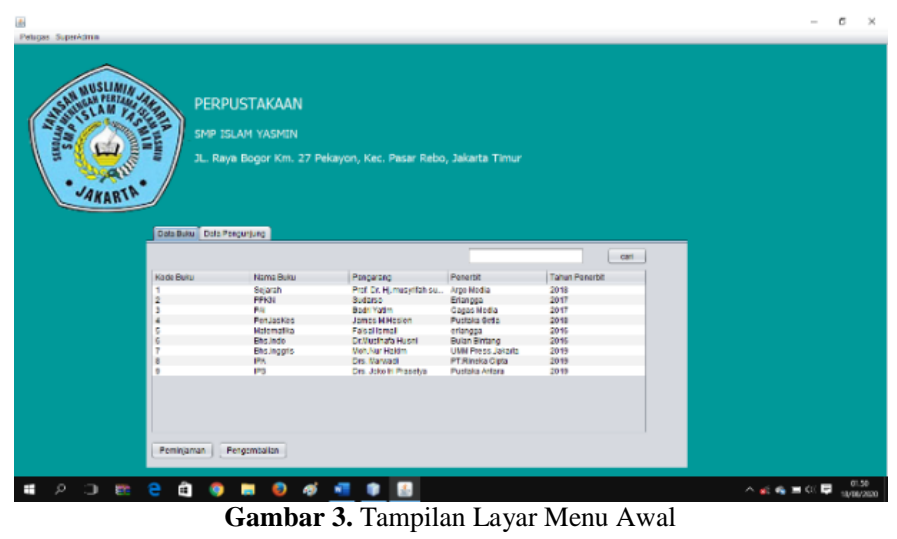

Layar diatas merupakan tampilan pada aplikasi perpustakaan SMP Islam Yasmin, tampilan ini terdapat pada awal program. Tampilan menu tidak memiliki login pembuka dan bisa digunakan oleh siswa, petugas dan superadmin. Hanya saja menu pada petugas dan superadmin harus login terlebih dahulu. Di menu ini terlihat jelas data absensi siswa yang telah berkunjung ke perpustakaan.

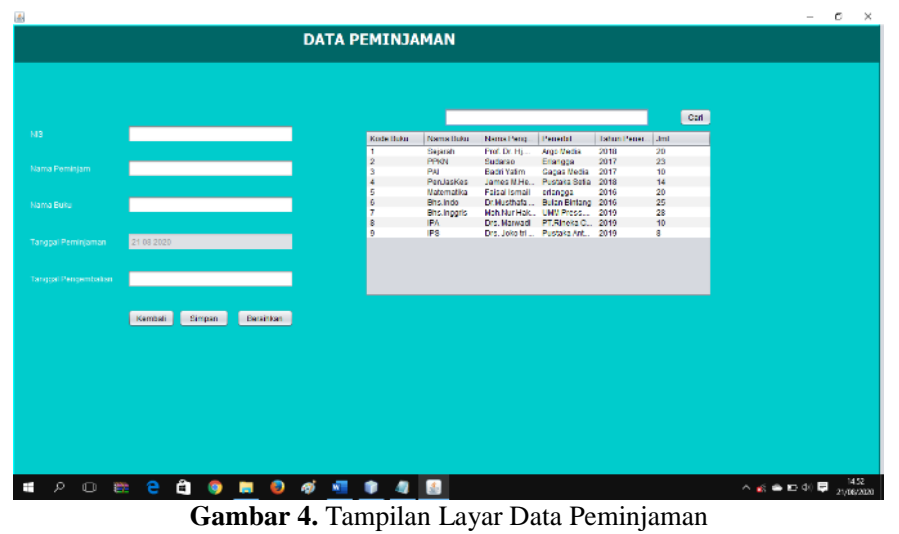

Layar diatas merupakan tampilan pada data peminjaman yang dimana terdapat tabel untuk melihat tanggal peminjaman dan tanggal pengembalian buku, menu ini hanya untuk siswa yang ingin meminjam buku.

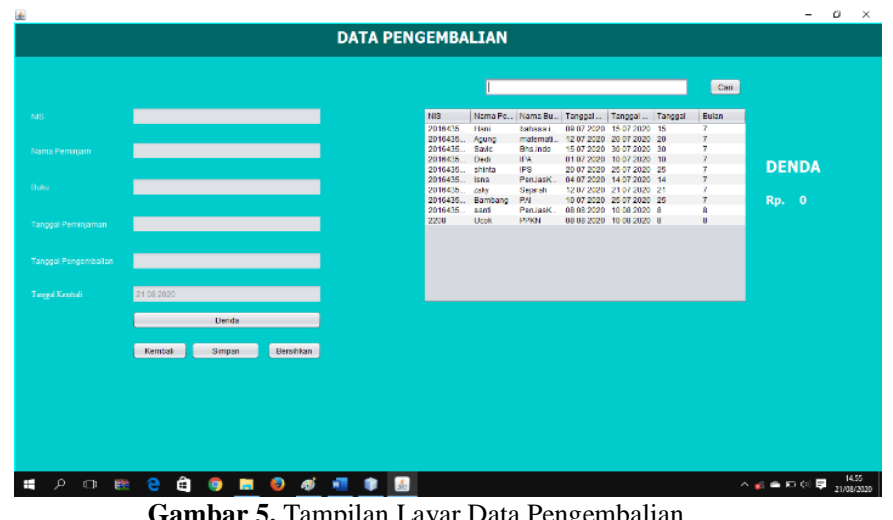

Gambar 5. Tampilan Layar Data Pengembalian

Layar diatas merupakan tampilan pada data pengembalian yang dimana terdapat tabel untuk melihat jatuh tempo pada saat siswa mengembalikan buku, menu ini hanya untuk siswa yang ingin mengembalikan buku. 


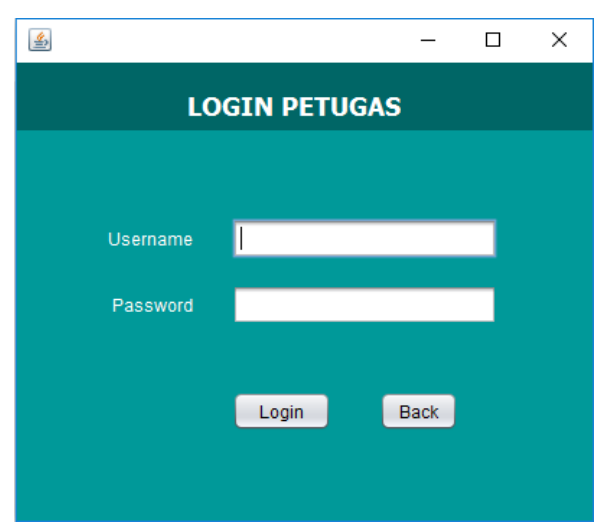

Gambar 6. Tampilan Login Petugas

Layar diatas merupakan tampilan login untuk masuk kedalam menu petugas, hanya petugas yang bisa masuk dan memiliki username dan password tersebut.

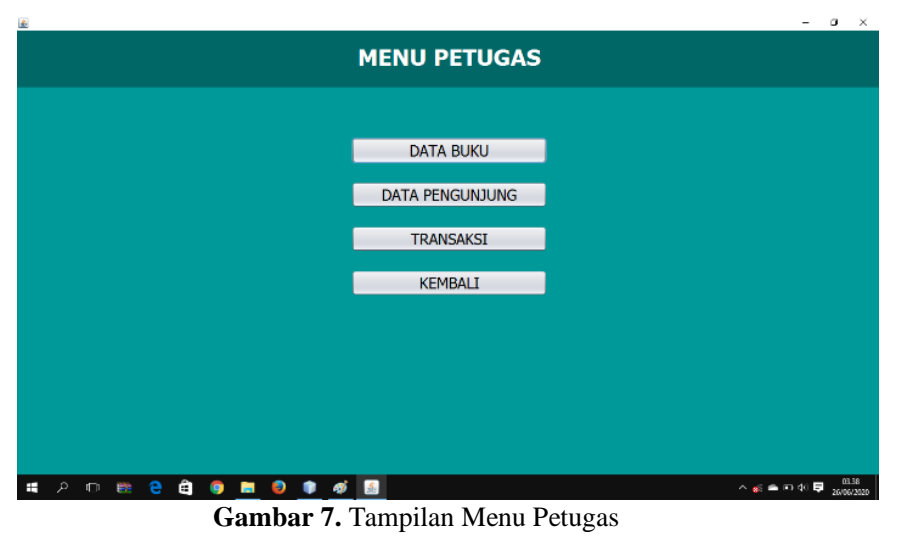

Layar diatas merupakan tampilan menu petugas yang dimana terdapat pilihan button (data buku, data absensi, data transaksi dan kembali).

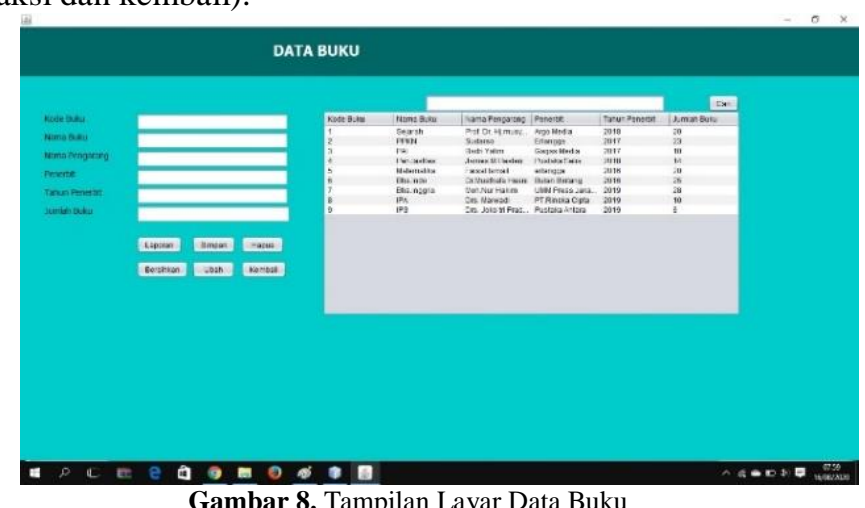

Layar diatas merupakan tampilan data buku yang dimana hanya petugas yang bisa mengisi data buku sesuai dengan stok buku yang ada di perpustakaan. 


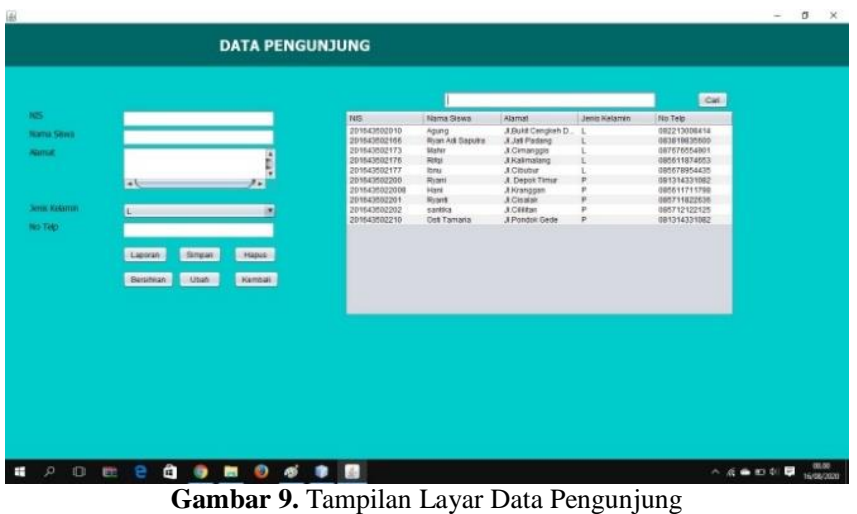

Layar diatas merupakan tampilan data absensi yang dimana hanya petugas yang bisa mengisi data absensi / pengunjung sesuai dengan siswa yang berkunjung di sistem perpustakaan.

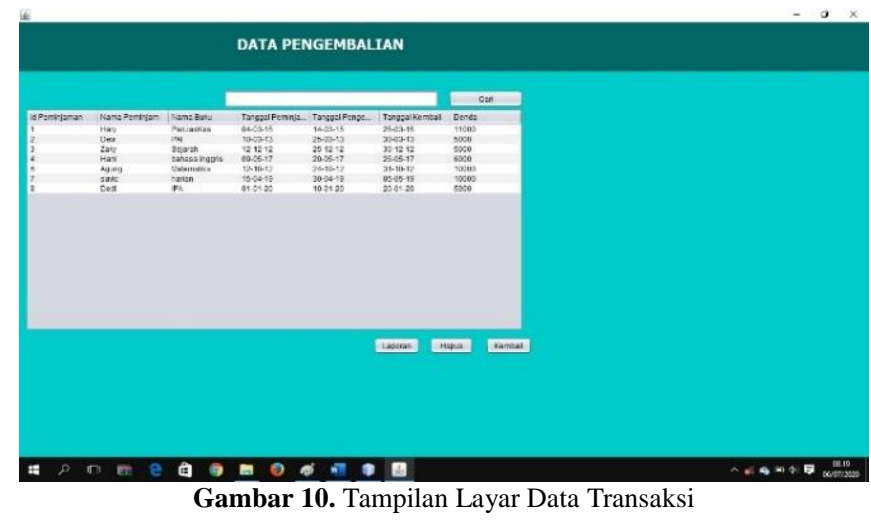

Layar diatas merupakan tampilan dari data transaksi yang dimana petugas hanya memilih data untuk pengembalian buku di sistem perpustakaan.

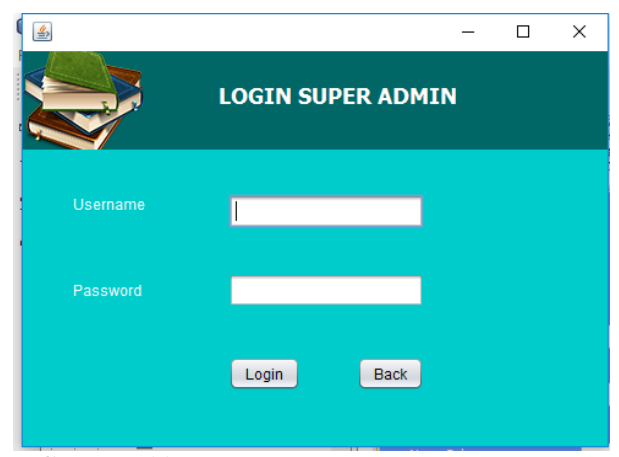

Gambar 11. Tampilan Layar Login SuperAdmin

Layar diatas merupakan tampilan login SuperAdmin untuk masuk kedalam data petugas, hanya SuperAdmin yang bisa masuk dan memiliki username dan password tersebut. 


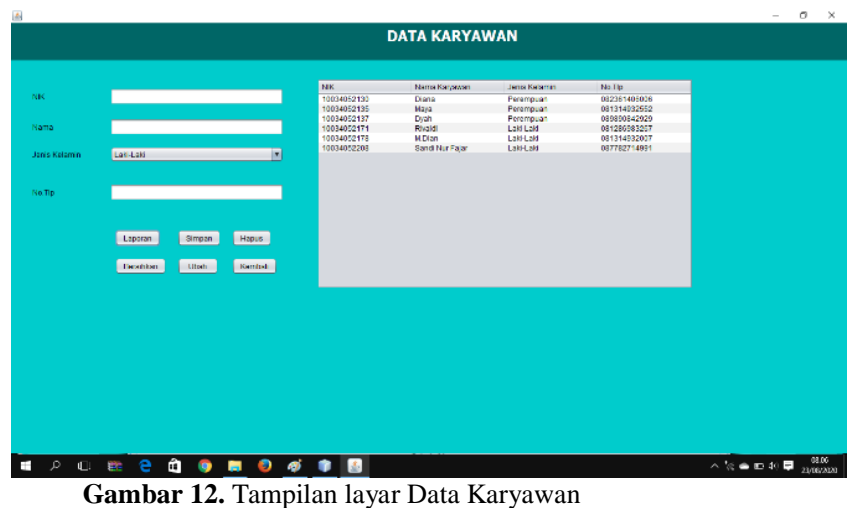

Layar diatas merupakan tampilan dari data karyawan yang dimana hanya superadmin yang bertugas untuk melihat karyawan / petugas perpustakaan yang sedang berpetugas di sistem perpustakaan.

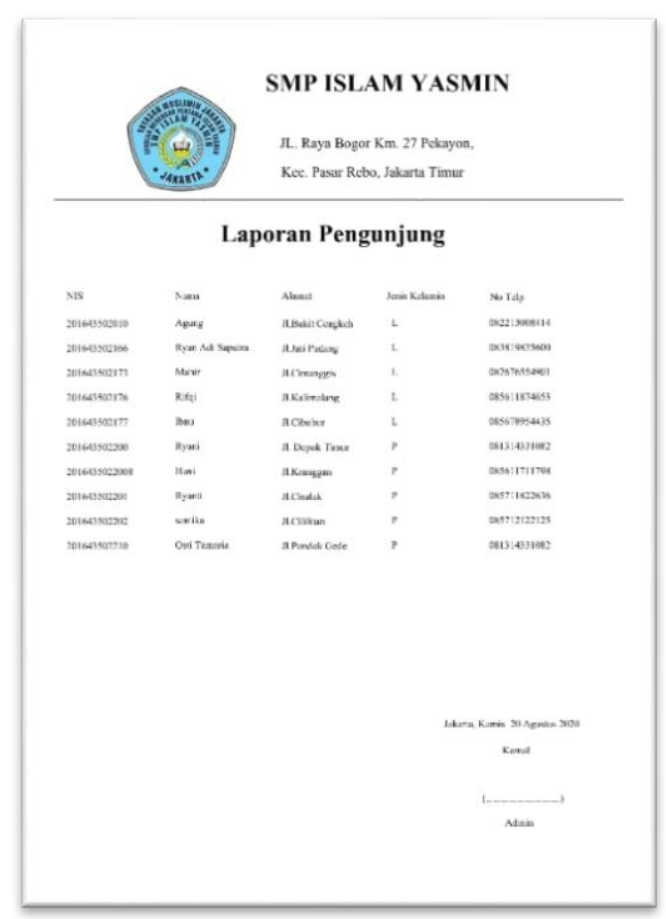

Gambar 13. Laporan Pengunjung

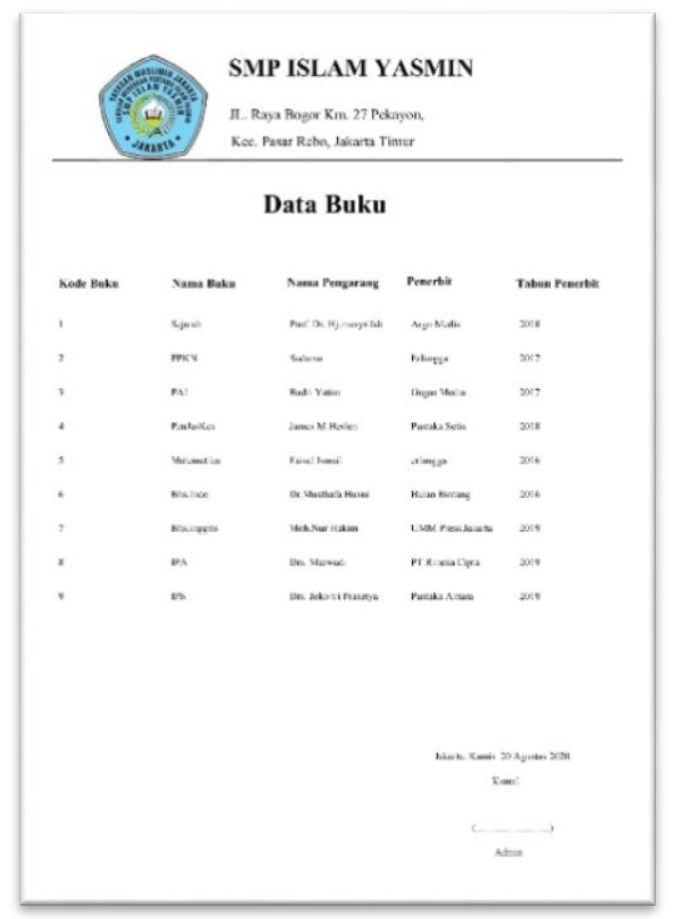

Gambar 14. Laporan Data Buku 


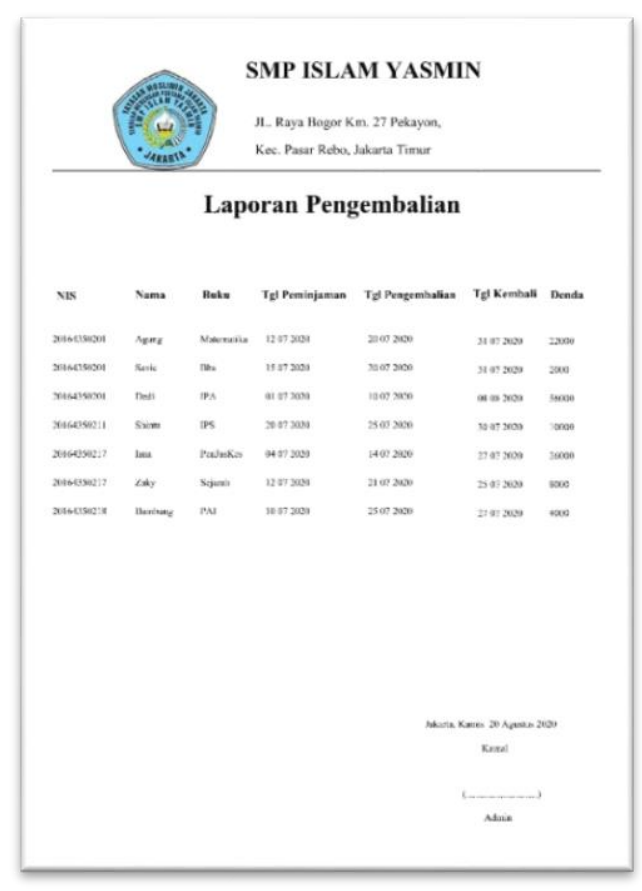

Gambar 15. Laporan Karyawan

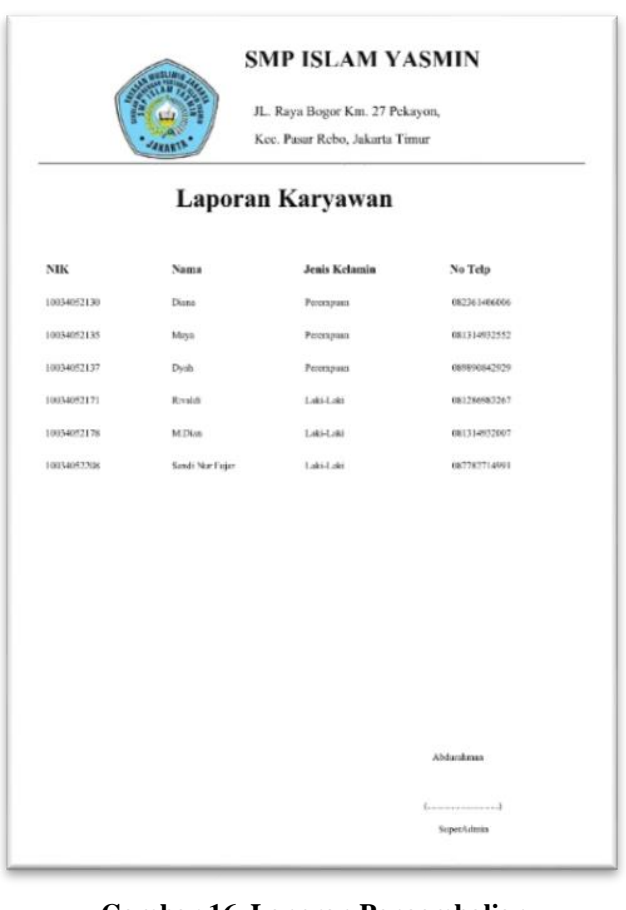

Gambar 16. Laporan Pengembalian

\section{Kesimpulan}

Dengan dibuatnya sistem perpustakaan di SMP Islam Yasmin semua proses pengolahan data pada permasalahan perpustakaan yang seblumnya dilakukan secara manual sekarang sudah tidak dilakukan dengan manual. Dengan adanya sistem ini semua proses-proses akan lebih terstruktur serta mempermudah penginputan yang didapat pada sistem ini.

\section{Daftar Pustaka}

[1] Cahyaningtyas Rosita. 2015. Perancangan Sistem Informasi Perpustakaan Pada Smp Negeri 3 Tulakan, Kecamatan Tulakan Kabupaten Pacitan. IJNS Vol. 4 No.2 ijsn.apmmi.org

[2] Darwati Ida. 2017. RANCANG BANGUN PEMINJAMAN DAN PENGEMBALIAN BUKU PADA PERPUSTAKAAN SEKOLAH DASAR. Jurnal Ilmu Pengetahuan dan Teknologi Komputer. Vol. 2 No.1. ISSN: 2527-4864

[3] Fajar Nugraha. 2014. Analisis dan Perancangan Sistem Informasi Perpustakaan. Jurnal SIMETRIS Vol.5 No.1 April. ISSN: 2252-4983

[4] Gustiana Dian. 2018. Sistem Informasi Pengolahan Data Perpustakaan Berbasis Desktop Pada Yayasan Pendidikan Tanimbar Lestari. IKRAITH Vol. 2 No.1

[5] Haryanto Dadang. 2019. PERANCANGAN APLIKASI PERPUSTAKAAN DI SMA DAN SMK PASUNDAN 2 KOTA TASIKMALAYA. JUMIKA Vol.6 No.1. e-ISSN: 2541-6316.

[6] Pangesti Vidia Esti. 2016. Sistem Informasi Perpustakaan Berbasis Web pada SD Muhammadiyah 4 Surabaya. JSIKA Vol.5 No.10. ISSN: 2338-137X

[7] Subtari. (2012). Konsep Sistem Informasi. Andi Offset

[8] Yakub. 2012. Pengantar Sistem Informasi. Grahara Ilmu

[9] Zuraidah Eva. 2019. PERANCANGAN APLIKASI ABSENSI SISWABERBASIS JAVA NETS BEANS. Jurnal PROSISKO Vol. No.1. ISSN: 2406-7733.

[10] Yorda Wira Aswin 1, Mudjianto 2, dan Retna Ningsih 3. 2020. Sistem Informasi Inventory Pada Hotel Maharani. Jurnal Nasional Komputasi dan Teknologi Informasi (JNKTI) Vol. 3. No.3. ISSN: 2620-8342. 